\title{
Desenvolvimento de um sistema de RPG para o ensino de Física
}

\author{
Development of a RPG system for teaching physics \\ Clayton Dantas de Sá ${ }^{1}$, Laura Paulucci*1@ \\ ${ }^{1}$ Universidade Federal do ABC, 09210-580, Santo André, SP, Brasil.
}

\begin{abstract}
Recebido em 04 de janeiro de 2021. Revisado em 17 de março de 2021. Aceito em 03 de setembro de 2021.
Neste trabalho é relatado o desenvolvimento de um sistema de regras para um jogo de RPG (do inglês, role playing game) educacional e sua utilização no ensino de física. Foi criado um livreto contendo uma introdução completa ao RPG, incluindo sistemas de criação de personagens, descrição das regras do jogo e indicações de como utilizá-lo em sala de aula. Também contém uma aventura para explorar conceitos básicos de dinâmica e astronomia tais como a estrutura do sistema solar, as leis de Kepler e as leis de Newton, aplicadas no contexto de uma aventura espacial. Este sistema foi testado em três turmas do ensino de jovens e adultos com o objetivo de verificar a aplicabilidade e aceitação do jogo como método de ensino. Os resultados indicam que a abordagem proporciona maior interação entre os alunos, envolvimento com o conteúdo didático e visualização de sua aplicabilidade a problemas reais. Foi de modo geral bem-aceito pelos estudantes, apesar da pouca ou nenhuma familiaridade prévia dos mesmos com a dinâmica do RPG, evidenciando a importância da utilização de atividades nas quais os alunos tornam-se agentes do conhecimento em sala de aula.
\end{abstract}

Palavras-chave: RPG, jogos, estratégia didática.

This work presents the development of a rule system specifically designed for a role playing game (RPG) with educational purposes, in particular for physics education. A book with a full introduction to RPG, including a system for creating characters, game rules description and its use in a classroom environment is presented. A story to explore basic concepts of dynamics and astronomy, such as the structure of the solar system and Kepler and Newton's laws has also been developed with a space adventure background. This system was applied in three classes of high school for young adults teaching groups for evaluation of the applicability and acceptance of the game by students as a didactic strategy. Results indicate that this approach allows for a greater interaction among students, greater involvement with scientific content and better visualization of its applicability to real life situations. It was broadly accepted by the students even considering the low or even non-existent previous knowledge of the game dynamics.

Keywords: RPG, games, didactic strategy.

\section{Introdução}

É notável que o professor do ensino básico atualmente enfrenta desafios relacionados ao engajamento estudantil tanto no quesito de manter a turma envolvida com a aula, tornando o conteúdo abordado relevante aos estudantes, como a estimulá-los a exporem suas dúvidas. Este quadro pode ser ainda mais sensível às disciplinas das ciências exatas, tipicamente vistas como difíceis pelos estudantes.

Diante deste quadro, desenvolvemos um jogo de RPG, abreviação de role playing game (jogo de interpretação de papéis, em uma tradução livre), no intuito de auxiliar o professor a trabalhar as questões mencionadas.

O uso do RPG na educação vem sendo estudado no Brasil desde a década de 1990, com o RPG Desafio dos Bandeirantes [1] sobre história brasileira, com elementos de fantasia e folclore. Um marco na área foi a realização

\footnotetext{
*Endereço de correspondência: laura.paulucci@ufabc.edu.br
}

do I Simpósio de RPG e Educação em maio de 2002 na cidade de São Paulo, impulsionando seu estudo e evidenciando os benefícios pedagógicos associados a esta metodologia de trabalho, com sua aplicação a diferentes disciplinas.

Dentre as características mais marcantes do jogo que se relacionam bem ao ambiente em sala de aula, destacase sua natureza cooperativa, na qual os participantes não assumem seus papéis-padrão de professor e aluno. Segundo Klimick [2],

\section{"O RPG pode trazer para a escola a in- teratividade e a participação no ensino, o aluno pode aprender ao mesmo tempo que vai utilizando o que está sendo aprendido".}

No caso particular de aplicar-se o RPG à sala de aula, uma questão importante, dado que o RPG não é um jogo conhecido pela maioria dos professores e alunos, é o estabelecimento da dinâmica e regras do jogo. Em muitas aplicações, verificamos que o sistema 
de regras não costuma ser apresentado ao leitor, seja por questões de direitos autorais ou por não ser o objeto direto do trabalho, ou é ainda bastante simplificado [3], não necessariamente facilitando o trabalho do educador inexperiente com esta abordagem didática, mas, ainda assim, interessado em aplicá-la em sala de aula.

Os sistemas comerciais de RPG são variados e podem, inclusive, ser encontrados gratuitamente na internet. Entretanto, eles não se mostram adequados para o uso em sala de aula ou para aventuras pedagógicas, sendo desenvolvido para uso lúdico [10, e bastante complexos em seu objetivo. Tentativas de utilizar tais sistemas em sala de aula resultam em trabalho extra do professor para entender o sistema e o adaptar.

Por exemplo, o sistema de jogo D\&D 5 $5^{\mathrm{a}}$ Edição [11] foi utilizado por Sitko 12 em um jogo de RPG pedagógico. Para tal foi necessário adaptar o livro do jogador de 320 páginas, um dos três necessários para a compreensão do sistema, para uso em sala de aula, de modo a eliminar o que não será essencial ao jogo:

\section{“(...) as características aproveitadas do jogo original são, em essência, a narrativa da situação e a resolução do problema apresen- tado; a utilização de elementos do jogo é usada somente para tais objetivos, ficando a cargo do mestre/professor decidir quando usar as rolagens de dado e interpretação, ou o conteúdo das aulas para o seguimento da aula/sessão de RPG". [12, p. 137]}

Há também outras questões relacionadas ao uso de sistemas comerciais: muitas vezes utilizam-se de um universo de fantasia fantástica, o que introduz um elemento de incongruência no jogo, não sendo adequado para tratar de assuntos científicos. Isto também teve que ser contornado em [12, p. 137]:

"Por conseguinte, para que os alunos criassem suas fichas adequadamente, foram eliminados da ficha de DED 5.0 os campos que não eram úteis para nossa aventura, assim como foram trocadas as características de dragões e guerreiros por naves espaciais $e$ astronautas".

Com base neste panorama, desenvolvemos e testamos um sistema de RPG para uso específico em sala de aula. Houve a preocupação em destacar seções específicas para: 1. orientar o uso do jogo em sala de aula; 2 . orientar a criação de histórias com conteúdo pedagógico; 3 . inserir questões sobre os temas abordados ao longo da aventura.

Estas preocupações não estavam vinculadas ao caso específico do ensino de física, nem o desenvolvimento do sistema de regras, tornando o sistema, em princípio, possível de ser utilizado em qualquer disciplina. No caso específico de teste do produto, utilizando-se aulas de física, optamos por substituir os cenários de fantasia fantástica por um cenário de ficção científica, em uma história na qual a colonização do sistema solar já é uma realidade. Desta forma, os problemas enfrentados pelos alunos ao longo da aplicação necessitam de conhecimento científico para a sua solução.

\section{O RPG e Educação}

O jogo de RPG foi criado na década de 1970 quando da adaptação de jogos de tabuleiro que simulavam combates militares para um novo tipo de jogo onde cada jogador controlaria a ação de um único personagem [13. O jogo evoluiu de uma simulação de combate para algo mais complexo e passou a ser sobre aventuras e as interações entre personagens.

Uma partida de RPG se desenvolve como uma pequena peça de teatro de improviso, onde um jogador especial, chamado de mestre ou narrador, tem como função manter os demais jogadores imersos na história, também chamada de aventura, estimulando a participação de todos. Ele é um agente da narrativa, experiente, conhecedor das regras, que descreve os cenários e as cenas nas quais os personagens, controlados pelos jogadores, devem atuar. A partir das descrições do narrador, os jogadores decidem as ações de seus personagens e o narrador avalia as consequências destas ações na história, cujos resultados podem depender de um elemento de aleatoriedade, tipicamente uma jogada de dados, respeitando-se o sistema de regras utilizado. Assim, um sistema de RPG deve ter regras para criação de personagens, descrever a mecânica do jogo, dar orientações ao narrador e sugestões de novas aventuras.

Por sua própria natureza, o RPG é um jogo colaborativo, no qual os objetivos a serem alcançados dependem da interação entre os jogadores e destes com o narrador, cujo papel é garantir a participação e o divertimento de todos os participantes do jogo. É justamente por esta característica cooperativa que muitos pesquisadores da área de ensino encontram motivação para seu uso pedagógico [2].

O RPG se mostra como um instrumento que auxilia os alunos a vivenciarem os conceitos estudados através do cotidiano do personagem. O universo ficcional do jogo faz o aluno utilizar conceitos, muitas vezes apresentados de forma abstrata em aulas tradicionais, nas atividades de seu personagem, trazendo mais familiaridade e fazendo com que ele visualize uma aplicação prática do seu conhecimento. Além disso, o aluno torna-se ativo sobre sua aprendizagem, e não mais espectador da aula ministrada pelo professor, através das ações e decisões a serem tomadas dentro do jogo.

Este tipo de estratégia didática tem sido utilizada em diferentes áreas. Podemos citar alguns exemplos nos campos da história [1, 9, 14, geografia [2, línguas 44, física 6, 8, 12, química [15, biologia 7] e em usos interdisciplinares [5]. Dentre aplicações mais recentes do 
jogo em sala de aula, destacamos algumas com temática similar à apresentada neste trabalho:

- um RPG para ensino de física [16], focado na relação entre ciência, tecnologia e sociedade, num futuro pós-apocalíptico, no qual é desenvolvido um manual para professores e alunos que pode, em princípio, ser adaptado a outras aventuras;

- o uso do RPG no ensino de ciências [17, em que é apresentada uma proposta maleável, com instruções simples para adaptação a diferentes temas;

- uma aventura de RPG [18, que desenvolve conceitos de física permeando o conteúdo dos três anos do ensino médio, enquanto os jogadores enfrentam diversos problemas ao tentar completar uma viagem de submarino entre a costa do Brasil e da África;

- e um RPG para o ensino de astronomia [19], envolvendo astronomia de posição em um cenário de navegações no final do século XVI, com a criação de "cartas de missões" para descentralizar o papel do professor como narrador da aventura, permitindo que vários grupos de alunos joguem simultaneamente.

São propostas interessantes que relatam melhoras motivacionais e de desempenho dos participantes. O trabalho de Ferreira-Costa et al. [16] aborda a questão do sistema de jogo, com orientações ao professor sobre a narração da história e um guia ao aluno focado na criação e evolução de personagens, sem eliminar completamente o teor de fantasia e criando um cenário fixo para o desenvolvimento da narrativa. Boas e colaboradores [18] utilizaram-se do sistema de regras desenvolvido por Amaral 13 para o desenvolvimento da narrativa, baseado em um sistema comercial. Já em [19], Mahlow et al. relatam acerca do desenvolvimento de dois manuais para auxiliar a aplicação do jogo porém estes não foram disponibilizados para consulta.

\section{Sistema de RPG Pedagógico}

O sistema de RPG pedagógico desenvolvido está em formato de livro, de título Narrativa: Sistema de RPG Para Uso Escolar - Livro do Professor, e disponível para download livre através do endereço http://gg.gg/nosx8 Ele também está disponível nas plataformas Google Books e Amazon. Este trabalho visa proporcionar todos os elementos necessários para que o professor possa aplicar a aventura proposta e também que possa criar as suas próprias, a partir do momento em que se sinta mais confortável com a dinâmica do jogo, sempre utilizando o mesmo sistema. O Quadro 1 apresenta os conteúdos presentes no livro com uma breve descrição.

A aventura que acompanha o jogo acontece no futuro e seu desenvolvimento permite aos alunos contato com alguns conceitos de astronomia e física. O aluno terá a oportunidade de desenvolver conhecimentos articulados sobre os movimentos de translação e rotação, aspectos gerais dos planetas do sistema solar, as três leis de Newton e as três leis de Kepler.

A aventura em si é destinada à leitura do narrador, não dos jogadores. Cada cena apresentada explica a situação dos personagens na história, às vezes na forma de uma descrição, outras na forma de problemas a serem resolvidos pelos personagens.

Quadro 1: Conteúdo do sistema de RPG pedagógico.

\begin{tabular}{|l|l|}
\hline Conteúdo & \multicolumn{1}{c|}{ Descrição } \\
\hline Guia rápido & $\begin{array}{l}\text { Resumo em formato de perguntas e respostas sobre o que é RPG e como } \\
\text { jogá-lo. }\end{array}$ \\
\hline \multirow{2}{*}{ Sistema de criação de personagens } & Sistema principal, baseado em pontos. \\
\cline { 2 - 3 } & Sistema rápido, para utilização em histórias mais simples. \\
\hline \multirow{2}{*}{ Atributos e Vantagens } & $\begin{array}{l}\text { Lista de possíveis características que os personagens podem possuir, } \\
\text { explicando como criá-los e como as escolhas dos jogadores podem interferir no } \\
\text { desenvolvimento do jogo. }\end{array}$ \\
\hline \multirow{2}{*}{ Perícias e Testes } & $\begin{array}{l}\text { Explicação da mecânica de testes utilizada no jogo, com exemplos. Descrição } \\
\text { das perícias que os personagens podem possuir e possibilidades de seus usos } \\
\text { em jogo. }\end{array}$ \\
\hline \multirow{2}{*}{ Narrador } & Como efetuar a condução de um jogo de RPG. \\
\cline { 2 - 3 } & $\begin{array}{l}\text { Bônus de questões como um mecanismo auxiliar de trabalhar o conteúdo } \\
\text { pedagógico no jogo. }\end{array}$ \\
\cline { 2 - 3 } & Sugestões para auxiliar o narrador no desenvolvimento de novas histórias. \\
\cline { 2 - 3 } & Como aplicar o jogo a uma turma escolar padrão. \\
\hline Aventura "Resgate Impossível” & $\begin{array}{l}\text { Aventura pronta para jogar, abordando conceitos de dinâmica e sistema solar. } \\
\text { Detalhes são apresentados no Quadro 2 }\end{array}$ \\
\hline Apêndice & Sugestões de leitura. \\
\hline
\end{tabular}


Como forma auxiliar de abordagem do conteúdo, foram instituídas questões a serem feitas aos alunos ao longo do desenvolvimento da história, procurando manter a relevância da questão com a cena apresentada. A resposta correta às questões rendiam pontos que os alunos podiam utilizar posteriormente como bônus em alguma jogada de dados. A proposta é que sejam estimulados a utilizar em situações consideradas difíceis (na qual o personagem deve atingir um valor elevado na soma dos dois dados mais o atributo, tipicamente maior que 14 pontos) de modo a manter o ritmo da história.

\section{Abordagem Didática}

O sistema de RPG pedagógico foi desenvolvido como parte dos requisitos para o título de mestre de um dos autores dentro do Mestrado Nacional Profissional em Ensino de Física 20. Ele foi aplicado em três turmas do ensino médio, modalidade EJA (ensino de jovens e adultos), da Escola Estadual Professora Olga Fonseca, na Cidade de Diadema-SP, com um total de 58 alunos.

O conteúdo de física/astronomia requerido na história foi previamente trabalhado na forma de uma Unidade de Ensino Potencialmente Significativa [21, sendo a aventura utilizada para revisão e fixação dos conteúdos. No entanto, podem ser criadas aventuras para introduzir conteúdos às turmas como forma de problematização [22.

Para a aplicação do jogo, os alunos foram divididos em grupos de quatro ou cinco alunos, onde cada grupo tornou-se responsável por interpretar um dos personagens. Optou-se por esta dinâmica porque ela reduz o número de personagens em jogo, facilitando assim o papel do narrador, e também coloca os alunos de um mesmo grupo em contato direto durante as discussões. Isto ajudou principalmente os alunos mais introvertidos que precisavam se manifestar em um grupo menor e sem tanta exposição perante a sala. Foram criados 7 personagens para a aventura, com habilidades que os permitem jogar mas sem perícias que possam resolver os problemas científicos da missão em uma jogada de dados.

O guia rápido de como jogar foi distribuído a todos os grupos de jogadores e foi feita uma leitura conjunta com o professor para discussão das regras. O jogo teve início com a descrição da cena inicial aos alunos, na qual seus personagens estão a caminho de Mercúrio quando sua nave sofre uma pane devido a uma erupção solar inesperada. A partir de então, eles devem descobrir se a nave sofreu danos, qual a extensão desses danos e qual a melhor estratégia para que todos possam voltar sãos e salvos para casa. A linha da história deve induzilos a consertar a nave e realizar uma acoplagem de emergência em uma estação espacial abandonada, já que não conseguirão voltar sozinhos à Terra ou seguir para Mercúrio devido à grande perda de combustível que a nave sofreu.
O conteúdo de física, além de ser explorado na mecânica de questões bônus, que podiam ser utilizadas para facilitar uma jogada de dados, surgia também no contexto da aventura. Quando, por exemplo, os personagens identificaram um vazamento de combustível na lateral da nave, foi necessário a compreensão da terceira lei de Newton para verificar que isto mudaria a trajetória da nave. Ao sair da nave para manutenção, eles discutiram, orientados pelo professor, como a primeira lei de Newton garantiria que eles não seriam "deixados para trás" pela espaçonave.

Ao final da experiência, os alunos foram convidados a responder a um questionário (anônimo) para aferir o grau de satisfação que tiveram com o RPG em sala de aula e sua percepção sobre a relação com o conteúdo didático e relacionamento interpessoais proporcionados pelo jogo.

A aplicação durou de duas a três aulas. Alguns detalhes da história e dos tópicos de física trabalhados podem ser consultados no Quadro 2

\section{Resultados}

As turmas do EJA apresentam diversas heterogeneidades intrínsecas desta modalidade de ensino, tais como idade, histórico de vida e ocupação profissional. Neste contexto de diferenças é que se inclui o RPG como uma ferramenta que pode ajudar a promover maior interação entre os alunos.

Por se tratar de uma novidade para os alunos e para o professor, o uso de um jogo em sala de aula produziu uma certa tensão inicial, principalmente quanto ao esclarecimento das regras. Para isso, uma leitura conjunta do guia rápido e das fichas de personagem foi feita. A participação geral dos grupos foi grande e houve oportunidade para sanar as dúvidas levantadas pelos alunos sobre as regras, inclusive sendo observada a primeira interação entre estudantes: os alunos que entenderam cuidaram de explicá-las para os demais participantes.

Percebemos algumas alterações na dinâmica entre os alunos durante o jogo em relação ao cotidiano da sala de aula. Normalmente, os mais jovens se comportavam de maneira mais dispersa durante as aulas e, quando precisavam de ajuda com as tarefas, recorriam aos mais velhos, que eram mais comprometidos com as atividades em sala. Durante as instruções do jogo, os mais jovens se interessaram mais e passaram a ajudar seus colegas mais velhos quando estes tinham dificuldades em entender as regras.

Durante o desenvolvimento da aplicação, cada grupo elegeu, de maneira orgânica, um porta-voz para interagir com o professor e com os demais grupos. Em alguns casos pôde-se perceber uma monopolização das interações por este porta-voz, e coube ao professor intervir nestes momentos. Quando tal intervenção era necessária, bastava o professor questionar o porta-voz com questões 
Quadro 2: Conteúdo da aventura "Resgate Impossível".

\begin{tabular}{|l|l|}
\hline Conteúdo Pedagógico & Movimento de translação e rotação \\
& Planetas do sistema solar e fonte de energia do Sol \\
& Leis de Kepler \\
& Leis de Newton \\
\hline Personagens jogadores & Annie Cannon - Médica \\
& Charles Messier - Técnico de manutenção de equipamentos \\
& Cecilia Payne - Engenheira mecânica \\
& Marry Someville - Piloto \\
& Jan Oort - Programador de computadores \\
& Sophie Brahe - Mecânica de equipamentos \\
& Pedro Simão - Condutor de veículos terrestres \\
\hline História & $\begin{array}{l}\text { Pequena introdução à estrutura da história, composta por cinco cenas. São explicadas } \\
\text { as funções das descrições de cenas e das questões a serem propostas aos alunos. }\end{array}$ \\
\cline { 2 - 3 } & $\begin{array}{l}\text { Cena 1: Evento que causa dano à nave. } \\
\text { Cena 2: Os alunos investigam a gravidade dos danos e como consertá-los. }\end{array}$ \\
& $\begin{array}{l}\text { Cena 3: Os alunos devem descobrir quais opções existem para prosseguir com a missão. } \\
\text { Cena 4: Os alunos devem corrigir manualmente a rota da nave em direção a uma } \\
\text { estação abandonada. } \\
\text { Cena 5: Os alunos devem acoplar na estação e realizar um reabastecimento para } \\
\text { seguirem rumo a Mercúrio. }\end{array}$ \\
\hline Euestões a serem propostas aos alunos. \\
\hline
\end{tabular}

do tipo - O que seus colegas do grupo acham disto? - ou ainda - Todos no grupo concordam com isto? Conversem um pouco antes de decidir.

Ainda que com algumas poucas evidências de tais monopolizações, a impressão qualitativa do professor é que o nível de participação dos alunos, comparado às aulas tradicionais, foi sensivelmente maior. A quantidade de conversas sobre assuntos não relacionados à atividade foi pouca ou até mesmo inexistente, o que demonstra o interesse e envolvimento dos alunos. Além disto, as respostas às questões bônus eram discutidas não só dentro do grupo ao qual eram feitas, mas entre os grupos (não era esta a dinâmica sugerida pelo jogo, cada grupo deveria responder a questão internamente, mas pelo bem da situação de aprendizado, a discussão entre os grupos não foi proibida, e sim estimulada).

Apesar do pouco conhecimento prévio dos estudantes sobre o RPG (dos 50 participantes, apenas 28\% afirmavam já conhecer o jogo de RPG, sendo que um número bem mais reduzido (10\%) havia de fato participado de alguma partida anteriormente), $52 \%$ dos alunos ficaram totalmente satisfeitos com a aplicação do produto enquanto outros $34 \%$ mostraram-se parcialmente satisfeitos. Este método de aprendizagem foi, de uma maneira geral, bem-aceito pelos alunos. Além disso, $57 \%$ dos alunos afirmaram que estariam totalmente satisfeitos com uma nova aplicação desta atividade, enquanto $31 \%$ estariam parcialmente satisfeitos.

Foi possível verificar uma maior interação entre os alunos, tendo sido este ponto avaliado positivamente pelos mesmos. De maneira geral, o jogo do RPG estimulou a interatividade entre os alunos participantes da atividade.
Também verificamos que um número reduzido de alunos não compreendeu completamente a dinâmica do jogo e não teve uma boa comunicação com os demais integrantes do seu grupo. Isso fez com que reavaliássemos o material do guia para o professor e aluno, incluindo fluxogramas e explicações mais detalhadas para facilitar o seu uso em sala de aula. Como é comum em jogos de RPG, durante a aplicação surgiram algumas situações não previstas no enredo da aventura, o que demanda um grau de improvisação do narrador/professor para manter o jogo em funcionamento. Pensando em auxiliar o professor inexperiente a lidar com este tipo de situação, o capítulo dedicado ao narrador foi ampliado, de modo a prepará-lo melhor. A versão disponível no link indicado já passou por revisões que levaram em conta os resultados de sua aplicação.

Um dos objetivos do uso do RPG em sala de aula é estimular a interação entre os alunos e aplicar o conteúdo trabalhado em um contexto que se aproxime mais de uma situação concreta. Para $89 \%$ dos alunos a atividade proposta contribuiu para o seu entendimento sobre os conteúdos trabalhados em sala de aula.

A recepção geral dos alunos em relação ao produto apresentado foi positiva, e este fato pode ser exemplificado em uma pequena amostra das respostas dos alunos à questão ${ }^{1}$

Aluno A: "Gostei muito da atividade. Foi divertido ao mesmo tempo educativo, gostaria que tivesse mais aulas

\footnotetext{
1 Transcrição literal das respostas dadas, sem correções de linguagem.
} 
assim, gostei da atividade em grupo e da maneira que eu pude imaginar a vida numa nave."

Aluno B: "Uma atividade diferente de todas. Professor muito legal faria você aprender muitos detalhes e saber o que fazer neste momento se estivesse passando. Muito obrigado gostei da sua aula fez abrir a minha mente."

Aluno C: "Em minha opinião, a atividade faz todos interagir fica mais fácil o aprendizado e faz com que os alunos se sintam mais a vontade na aula fica mais criativa e assim mais fácil de aprender."

Aluno D: "Eu particularmente gostei muito do RPG, achei dinâmico e divertido, facilitou o meu aprendizado na matéria. No próximo semestre quero jogar novamente."

Aluno E: "Atividades desse tipo deveria ser aplicada mais vezes, não fica aquela aula maçante, chata, e fica mais fácil lembrar as matérias e ver onde pode ser aplicado na prática."

\section{Considerações Finais}

A elaboração de um sistema de regras de RPG voltado para a educação, em particular para o ensino de física, resultou de uma preocupação em facilitar e difundir a aplicação do RPG em sala de aula. Desta forma, buscouse desenvolver um sistema de jogo simples e especificamente voltado para aplicações educacionais para auxiliar professores no uso desta ferramenta didática, tenham eles conhecimento prévio sobre o jogo ou não.

Esta proposta foi testada em turmas do ensino de jovens e adultos, mostrando ter sido uma metodologia viável e bem-aceita por alunos do ensino médio. O jogo foi utilizado como forma de revisão de conteúdo sobre gravitação com o uso de uma história criada especificamente para tal, que explorava um cenário de ficção científica envolvendo uma viagem interplanetária na qual os alunos eram surpreendidos por situações que ameaçavam a vida dos tripulantes. Através do uso de conceitos físicos, eles deveriam buscar soluções para consertar sua nave e ficarem em segurança.

Verificamos que o projeto proporcionou um aumento sensível no envolvimento e interação entre os alunos durante o jogo, em relação às aulas tradicionais, em particular nas discussões sobre como os conceitos científicos trabalhados influenciavam as ações de seus personagens. O jogo aumentou o interesse dos alunos na aula e no conteúdo abordado.

A análise das respostas dos alunos a um questionário pós-aplicação mostrou que $86 \%$ deles ficaram satisfeitos ou muito satisfeitos com a experiência, e que também gostariam que este tipo de atividade fosse aplicada novamente. Além disso, todos os alunos perceberam a relação entre os conteúdos abordados dentro do jogo e o conteúdo previamente trabalhado em sala de aula.

O sistema de regras desenvolvido revelou-se simples de ser aplicado, capaz de cativar a atenção dos alunos e melhorar seu envolvimento em sala de aula. Buscaremos avançar com este projeto a partir do desenvolvimento de novas histórias para explorar outros temas e ajudar o professor a adquirir experiência antes de tentar desenvolver suas próprias histórias. Além disso, pretendemos desenvolver aventuras que, em vez de funcionarem para fixação de conceitos, sejam capazes de introduzir novos conteúdos. Ou seja, este projeto continua em andamento, desde sua primeira execução, e desenvolvimentos futuros estarão disponíveis em www.plantaofisica.blogspot. com.br.

\section{Agradecimentos}

O presente trabalho foi realizado com apoio da Coordenação de Aperfeiçoamento de Pessoal de Nível Superior Brasil (CAPES) - Código de Financiamento 001.

\section{Referências}

[1] C.K. Pereira, F.M. Andrade e L.E.R. Freitas, Desafio dos Bandeirantes - Aventuras na Terra de Santa Cruz (GSA, Rio de Janeiro, 1992).

[2] C.E. Klimick, em: I Simpósio RPGÉEducação (São Paulo, 2002).

[3] R. Samagaia e L.O.Q. Peduzzi, Ciência \& Educação 10, 259 (2004).

[4] M.L. Malato e A.M. Fonseca Viegas, Videtur 31, 37 (2005).

[5] S.M. Pacheco e R.R.D. Amaral, em: III Congresso Internacional de Tecnologia na Educação (Pernambuco, 2010).

[6] M.A.S. Sousa, O potencial do RPG como instrumento de avaliação no ensino dos conceitos iniciais de Termodinâmica. Trabalho de Conclusão de Curso, Universidade Federal do Piauí, Teresina (2011).

[7] A.A. Oliveira Neto e S.A. Benite-Ribeiro, Itinerarius Reflectionis 8 (2012).

[8] M.A.S. Sousa e B.V.C. Silva, Experiências em Ensino de Ciências 9, 12014 (2014)

[9] D.R. Sabka, Uma abordagem CTS das máquinas térmicas na revolução industrial utilizando o RPG como recurso didático, Dissertação de Mestrado, Universidade Federal do Rio Grande do Sul, Porto Alegre (2016).

[10] F.A. Nascimento Júnior e M. Pietrocola, em: $V$ ENPECEncontro Nacional de Pesquisa em Educação em Ciências (Bauru, 2005).

[11] J. Crawford, J. Wyatt, R.J. Schwalb e B.R. Cordell, Player's Handbook DESD (Wizards of the Coas, Renton, 2014).

[12] C.M. Sitko, B.R. Dall Pozzo e C.C. Lobo, Revista EDaPECI 19, 134 (2019).

[13] R. Vasques, As potencialidades do RPG na educação escolar. Dissertação de Mestrado, Universidade Estadual Paulista, Araraquara (2008).

[14] R.R. Amaral e H.F.B.N. Bastos, Revista Brasileira de Pesquisa em Educação em Ciências 11, 103 (2011).

[15] E.L.D. Cavalcanti e M.H.F.B. Soares, Revista Electrónica de Enseñanza de las Ciencias 8, 255 (2009). 
[16] P.H.S. Silva, O RPG (Role-Playing game) como uma ferramenta para o ensino de Física. Dissertação de Mestrado, Universidade Federal do Rio de Janeiro, Rio de Janeiro (2016).

[17] N.J. Guzzi Filho, F.S. dos Santos, L.S.B. Santos e C.A.S. Peixoto, em: XI ENPEC-Encontro Nacional de Pesquisa em Educação em Ciências (Florianópolis, 2017).

[18] A.C.V. Boas, A.G. Macêna Júnior e M.M.P. Dias, Caderno Brasileiro de Ensino de Física 34, 372 (2017).

[19] F.R.P. Mahlow, R.M.F. Scalvi, M.F. Scalvi e G.G.F. Ramos, Experiências em Ensino de Ciências 15, 263 (2020).

[20] C.D. Sá, Desenvolvimento e aplicação de um sistema de RPG para o ensino de física para alunos do Ensino Médio. Dissertação de Mestrado, Universidade Federal do ABC, Santo André (2017).

[21] M.A. Moreira, Aprendizagem Significativa em Revista 1, 43 (2011).

[22] F.A. Nascimento Júnior e M. Pietrocola, Revista de Enseñanza de la Física 27, 675 (2015). 